\title{
Isothermal Crystallization Kinetics of Poly(lactic acid) Stereocomplex/Graphene Nanocomposites
}

\author{
Diego H. S. Souza ${ }^{a}$, Patricia V. Santoro ${ }^{a}$, Marcos L. Dias ${ }^{a *}$ \\ anstituto de Macromoléculas Professora Eloisa Mano - IMA, Universidade Federal do Rio de Janeiro - \\ UFRJ, Av. Horácio Macedo, 2.030, 21941-598, Rio de Janeiro, RJ, Brazil.
}

Received: April 05, 2017; Revised: September 20, 2017; Accepted: November 10, 2017

\begin{abstract}
The isothermal crystallization kinetics of PLA stereocomplex (scPLA) and scPLA/graphene oxide nanocomposites was investigated. scPLA was prepared by symmetric blending the two isomers, PLLA and PDLA and the scPLA nanocomposite by polymerization of the respective lactides in presence of commercial graphene oxide nanoplatelets $\left(\mathrm{GNPO}^{+}\right)$followed of blending the two composites. The effect of the filler on the crystallization behavior and thermal properties of scPLA was investigated by using differential scanning calorimetry (DSC). Avrami equation was used to describe the isothermal crystallization kinetics and melting behavior. Addition of $0.5 \mathrm{wt} \% \mathrm{GNPO}^{+}$to PLA matrix increases the crystallization rate, lowering the half-time of crystallization $t_{1 / 2}$ to around 5.5 min for scPLA nanocomposites, which is about $2.7 \mathrm{~min}$ below that found for scPLA when isothermally crystallized at $165^{\circ} \mathrm{C}$. During the isothermal crystallization, homochiral and stereocomplex crystals are formed, depending on the crystallization temperature. As crystallization temperature reaches 160 and $165^{\circ} \mathrm{C}$, the crystallization of homocrystals become prevented and only stereocomplex crystals are formed.
\end{abstract}

Keywords: poly(lactic acid), stereocomplex, crystallization, graphene, nanocomposites.

\section{Introduction}

Poly(lactic acid) (PLA) is a biopolymer widely used as an alternative to petroleum-derived polymers ${ }^{1}$. It has two isomeric forms, poly(L-lactic acid) (PLLA) and poly(D-lactic acid) (PDLA) that when blended either from solution or melt can result in stereocomplexation. PLA stereocomplex (scPLA) formed from these blends contains stereocomplex crystallites (sc-crystallites) which are quite different from the PLLA or PDLA homocrystallites ${ }^{2-5}$.

Formation of sc-crystallite has been extensively studied, since it gives PLA-based materials with higher thermal, mechanical, and hydrolysis resistances, thus opening a new way to produce biodegradable materials with different properties and applications ${ }^{6,7}$. For instance, while PLLA and PDLA present a melting temperature of $175-178^{\circ} \mathrm{C}$, sc-PLA can have a melting temperature up to $70^{\circ} \mathrm{C}$ higher ${ }^{8}$.

The majority of the reports on the crystallization of sc-PLA is related to the formation of sc-crystals in PLLA/ PDLA blends of different proportions, in block copolymers containing blocks of both isomers ${ }^{8-11}$, and studies of addition of small amounts of PDLA to PLLA to create sc-crystals in order to have nucleating effect on PLLA crystallization ${ }^{12-16}$.

The effect of fillers on the sc-crystallization has received less attention, but it has been also reported for some authors. For example, a study on the addition of talc in PLLA and in asymmetric 92:8 and 75:25 PLLA:PDLA blends was reported by $\mathrm{Nam}^{17}$. The study aimed to see the nucleating effect on the formation of scPLA and enhancement of crystallization rate

*E-mail: mldias@ima.ufrj.br and mechanical properties of PLLA. It was demonstrated that the filler acted as nucleating agent and was more effective in PLLA homocrystals than in the sc-crystals.

The nucleating effect of carbon nanotubes (CNT) on PLLA/PDLA blends was also recently reported ${ }^{18,19}$. The incorporation of CNTs leads to a lower crystallization activation energy and crystallinity enhancement in solutioncasting samples. In the case of multiwalled carbon nanotubes (MWCNT) in blends of equimolar enantiomeric PLA, mild thermal treatment extended the processing window for preparation of polylactides exclusively crystallized in the stereocomplex form.

Recently, graphene nanoplateles (GNPs) have attracted considerable attention as reinforcing nanofiller for polymer nanocomposites due to their high intrinsic mechanical strength and elastic modulus as well as high surface area.

$\mathrm{Sun}^{20}$ has investigated the incorporation of graphene oxide (GO) nanofillers to PLLA. GO was incorporated as GO-gPDLA synthesized using modified GO as initiator. The filler addition leads to a lower crystallization activation energy of scPLA, mainly due to the heterogeneous nucleating effect of the well-dispersed PDLA covalently bonded GO sheets. The author observed that in cold crystallized samples, low crystallinity is observed due to GO sheets which reduced chain mobility and hindered crystal growth.

In this work, the crystallization scPLA/graphene nanocomposites is also reported. Our studies focused mainly symmetric PLLA/PDLA blends with the aim to investigate the crystallization behavior of this blend in presence of commercial 
graphene oxide nanoplates. It aims also to elucidate the influence of this type of filler on the crystallization kinetics of scPLA from the melt under isothermal condition.

\section{Experimental}

\subsection{Materials}

L-lactide and D-lactide from Purac (Purasorb L and D, respectively) were purified by recrystallization from toluene. Graphene nanoplatelets HDPlas, GNPs grade 4, $\mathrm{O}_{2}$ functionalized $\left(\mathrm{GNPO}^{+}\right)$(lateral dimensions 1-2 $\mu \mathrm{m}$, surface area above $750 \mathrm{~m}^{2} / \mathrm{g}$ ) purchased from Cheap Tubes (Brattleboro, VT, USA) were used to prepare the nanocomposites.

\subsection{Sample preparation}

PLLA and PDLA were synthesized via ring opening polymerization of L-lactide and D-lactide using tin octanoate as initiator with a monomer/initiator molar ratio of 2500 . Polymerizations were carried out in Schlenk flasks at $180^{\circ} \mathrm{C}$ for $1 \mathrm{~h}$. The solid polymer obtained from polymerizations was dissolved in chloroform and precipitated in an excess of cold ethanol, filtered and dried in oven at $50^{\circ} \mathrm{C}$ overnight. The same reaction procedure was done in the presence of $0.5 \mathrm{wt} \%$ of $\mathrm{GNPO}^{+}$. Stereocomplexes were obtained by precipitation of PLLA/PDLA 1:1 blends (weight) in ethanol from chloroform solution.

\section{$2.3 X$-ray diffraction $(X R D)$}

$\mathrm{X}$-ray diffraction (XRD) analyses were performed on a Rigaku Miniflex (model DMAX 2200) X-ray diffractometer (30 kV, $15 \mathrm{~mA}, \mathrm{CuK} \alpha$ radiation, $\lambda=0.154 \mathrm{~nm}$ ) in the range of $2 \theta=2-40^{\circ}$. The XRD patterns were submitted to a deconvolution treatment with free peak-fitting software fityk (downloaded at http://fityk.nieto.pl/) to calculate the degree of crystallinity of the stereocomplexes. The degree of crystallinity was calculated after deconvolution of the XRD patterns using the equation below:

$$
\chi_{c}=\frac{A_{c}}{A_{a}+A_{c}} \cdot 100
$$

where, $\chi_{c}$ is the degree of crystallinity, $\mathrm{A}_{\mathrm{c}}$ is the total area of the crystalline peaks, and $\mathrm{A}_{\mathrm{a}}$ is the halo amorphous area.

\subsection{Thermogravimetric analysis (TGA)}

Thermogravimetric analyses were performed using a Q500 Thermoanalyser from TA Instruments. Measurements were carried out in nitrogen atmosphere at a heating rate of $10^{\circ} \mathrm{C} / \mathrm{min}$ up to $700^{\circ} \mathrm{C}$.

\subsection{Differential scanning calorimetry (DSC)}

DSC analysis was used to study the isothermal crystallization behavior and thermal properties of scPLA and scPLA/GNPO ${ }^{+}$ nanocomposite. A Perkin-Elmer DSC 7 was used. Samples of about $13 \mathrm{mg}$ were thermally treated as follow: 1) heating from 30 to $250^{\circ} \mathrm{C}$ at $20^{\circ} \mathrm{C} / \mathrm{min}$ and held for $3 \mathrm{~min}$ to erase the thermal history; 2) rapid cooling at $100^{\circ} \mathrm{C} / \mathrm{min}$ to the prescribed crystallization temperature $\left(90-165^{\circ} \mathrm{C}\right)$ and held for enough time to fully crystallize, then cooled at the same rate to $30^{\circ} \mathrm{C}$ and held for $3 \mathrm{~min}$, and 3) $2^{\circ}$ heating from 30 to $250^{\circ} \mathrm{C}$ at $10^{\circ} \mathrm{C} / \mathrm{min}$. The analyses were carried out under nitrogen atmosphere using flow rate of $20 \mathrm{~mL} / \mathrm{min}$. The degree of crystallinity was calculated from the endothermic peak and calculated from the equation below:

$$
\chi_{c}=\frac{\Delta H}{\Delta H^{0}}
$$

where $\Delta \mathrm{H}$ and $\Delta \mathrm{H}^{0}$ are the enthalpies of fusion for the sample and the $100 \%$ crystalline polymer, respectively. The $\Delta \mathrm{H}^{0}$ used for the $100 \%$ crystalline scPLA was $155 \mathrm{~J} / \mathrm{g}^{21}$ and for the $100 \%$ crystalline PLA was $106 \mathrm{~J} / \mathrm{g}^{22}$.

\section{$2.6 \mathrm{Gel}$ permeation chromatography (GPC)}

GPC was carried out in a Shimadzu LC 20 instrument equipped with a Shim-pack GPC-804 column and a RID-20A differential index detector. GPC analyses were performed using chloroform as eluent with flow rate of $1 \mathrm{~mL} / \mathrm{min}$ at $25^{\circ} \mathrm{C}$ and a polystyrene calibration curve. Number average $\left(M_{n}\right)$ and weight average $\left(M_{w}\right)$ molecular weights as well as polydispersity $\left(\mathrm{M}_{\mathrm{w}} / \mathrm{M}_{\mathrm{n}}\right)$ were determined by the Shimadzu software. PLA/graphene nanocomposites were solubilized in chloroform and the solutions filtered in Millipore filter of 0.22 micrometer porosity before being analyzed by GPC.

\section{Results and Discussion}

Molecular weight characterization of PLLA and PDLA matrix of the PLA/graphene nanocomposite obtained by in situ polymerization of lactides in presence of graphene were done by GPC. PLLA presented $M_{n}=108,000, M_{w}=210,700$ and $M_{w} / M_{n}=1.95$; while PDLA showed $M_{n}=95,900, M_{w}=$ 205,100 and $M_{w} / M_{n}=2.1$.

$\mathrm{XRD}$ analysis is one of the most valuable tools used for scPLA characterization due to the remarkable differences between the diffraction patterns of the stereocomplexes and homochiral PLA. Figure 1 shows the XRD patterns of the stereocomplexes prepared. It can be seen that both patterns show the same three peaks around 12,21 , and $24^{\circ}$ which are related to the formation of PLA stereocomplexes crystallized in a triclinic unit cell. ${ }^{21,23}$ The degree of crystallinity calculated for the stereocomplex PLA and scPLA/GNPO ${ }^{+}$nanocomposite was 36.4 and $41.3 \%$, respectively. This increase in the degree of crystallinity suggests that the graphene acted as a nucleating agent.

The thermal stability of the stereocomplexes was studied by TGA. Figure 2 shows the weight loss versus temperature for the scPLA and scPLA/GNPO ${ }^{+}$nanocomposite. Both materials presented only one step of degradation and the 


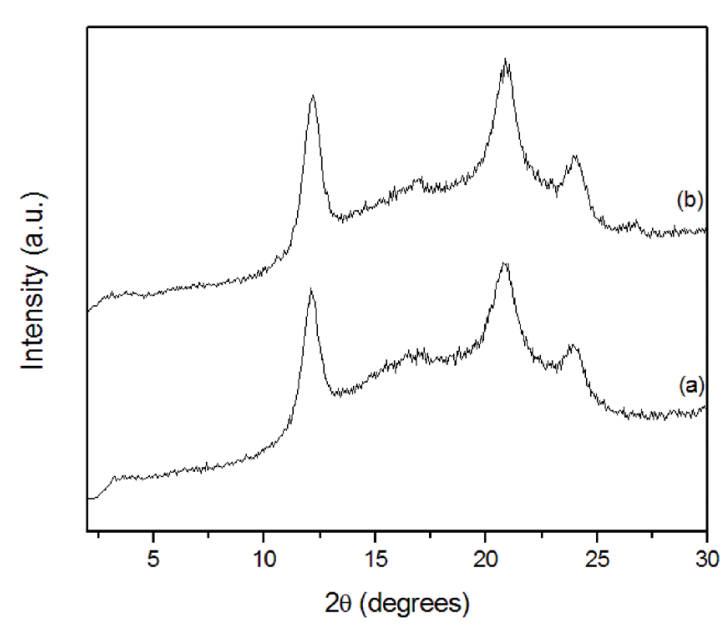

Figure 1. XRD patterns of (a) scPLA and (b) scPLA/GNPO+ nanocomposite.

TG curves of the nanocomposite show a decrease in thermal stability compared to neat scPLA. The onset temperature $\left(\mathrm{T}_{\text {onset }}\right)$ and the maximum decomposition temperature $\left(\mathrm{T}_{\text {peak }}\right)$ obtained from the TG curves are shown in Table 1. This decrease in thermal stability was associated to the hydroxyl, carboxylic acid and epoxy groups present in the $\mathrm{GNPO}^{+}$, which catalyze the degradation of PLA.



Figure 2. TGA curves of scPLA and scPLA/GNPO+ nanocomposite.

Figure 3 shows the heat flow curves of the first heating obtained from DSC for the materials studied. It can be observed that only sc-crystals were formed after precipitation of scPLA and scPLA/GNPO ${ }^{+}$nanocomposite, which shows a unique melting temperature $\left(\mathrm{T}_{\mathrm{m}}\right)$ at 220.3 and $220.8^{\circ} \mathrm{C}$, respectively.

The degree of crystallinity calculated for the stereocomplexes without and with $\mathrm{GNPO}^{+}$calculated from XRD was 38.2 and $43.5 \%$, respectively. These values are in agreement with what could be expected, since graphene platelets may act as nucleating agent for sc-crystals formation, increasing the overall degree of crystallinity of PLA.
Table 1. Onset temperature $\left(\mathrm{T}_{\text {onset }}\right)$, maximum decomposition temperature $\left(\mathrm{T}_{\text {peak }}\right)$ of scPLA and and scPLA/ $\mathrm{GNPO}^{+}$nanocomposite

\begin{tabular}{lcc}
\hline \multirow{2}{*}{ Material } & \multicolumn{2}{c}{ Degradation temperatures $\left({ }^{\circ} \mathrm{C}\right)$} \\
& $\mathrm{T}_{\text {onset }}$ & $\mathrm{T}_{\text {peak }}$ \\
\hline scPLA & 287 & 300 \\
scPLA $/ \mathrm{GNPO}^{+}$ & 278 & 290 \\
\hline
\end{tabular}

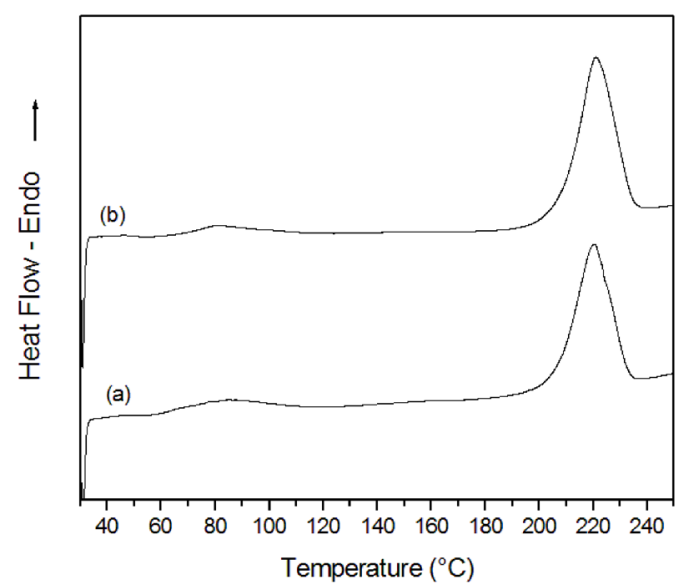

Figure 3. DSC curves of the first heating: (a) scPLA and (b) scPLA/ $\mathrm{GNPO}+$ nanocomposite.

\subsection{Isothermal crystallization}

Isothermal melt-crystallization of scPLA and scPLA/ $\mathrm{GNPO}^{+}$nanocomposite were investigated at different crystallization temperatures $(90,105,120,135,150,155$, 160 and $165^{\circ} \mathrm{C}$ ). Figures 4 and 5 show the isothermal crystallization exotherms of scPLA and scPLA/GNPO respectively. According to the exothermic peaks, the addition of $\mathrm{GNPO}^{+}$into the PLA matrix has a significant effect on the crystallization behavior of the material, which shows that the complete crystallization takes place in shorter times.

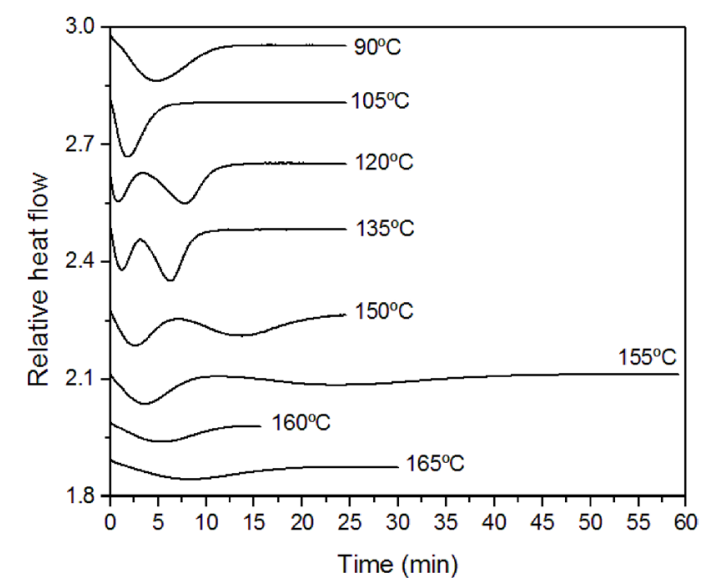

Figure 4. DSC curves of isothermal crystallization at different temperatures for scPLA. 


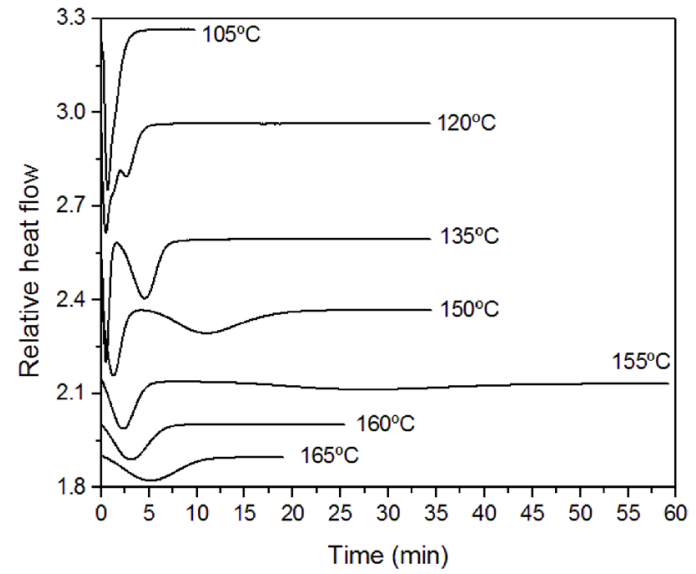

Figure 5. DSC curves of isothermal crystallization at different temperatures for scPLA/GNPO+ nanocomposite.

For both materials, formation of homocrystals together with sc-crystals seems to be highly influenced by the crystallization temperature $\left(\mathrm{T}_{\mathrm{c}}\right)$. At $\mathrm{T}_{\mathrm{c}}$ of 90 and $105^{\circ} \mathrm{C}$, it was not possible to distinguish between the crystallization related to homo and sc-crystals. At these temperatures, the existence of both crystals can be proved by DSC curves obtained by heating the materials after crystallization (See next section).

It is important to mention that the literature reports that PLLA can also crystallize into a $\alpha^{\prime}$ crystal modification when it is crystallized below $120^{\circ} \mathrm{C}^{24-27}$. Kawai at al ${ }^{1}$ demonstrated that this limit disordered $\alpha^{\prime}$ form, which has hexagonal packing, is obtained only below $90^{\circ} \mathrm{C}$. Thus, it is possible that the homo-crystals are in all case of the more ordered and stable $\alpha$ form, excepting in the sample crystallized at $90^{\circ} \mathrm{C}$. The formation of this crystal modification was not investigated here since it was not in the scope of the work.

At $\mathrm{T}_{\mathrm{c}}$ of $120,135,150$ and $155^{\circ} \mathrm{C}$, crystallization profiles showing the formation of both crystals at different temperature range was clearly observed. The fastest crystallization occurs for the high melting temperature sc-crystal. As the temperature increases, more distinct becomes the curves and more time is required for the complete crystallization of each crystal form. When crystallization temperature reaches 160 and $165^{\circ} \mathrm{C}$, the crystallization occurs as only one process and probably with predominance of sc-crystal, since the Tc is relatively close to homo-crystal melt. This assumption can be supported by the DSC curves of heating of these samples after the isothermal crystallization (see next section), in which a cold crystallization is observed.

With the addition of $\mathrm{GNPO}^{+}$, the crystallization becomes even faster regardless of the crystal form, which means that $\mathrm{GNPO}^{+}$acted as a nucleating agent.

Isothermal crystallization kinetics can be better visualized by evaluating the degree of crystalline conversion as a function of time at a constant temperature. The relative crystallinity at different crystallization time, $\alpha$, was then calculated according to the following equation:

$$
\propto=\frac{\int_{o}^{t}(d H / d t) d t}{\int_{o}^{\infty}(d H / d t) d t}
$$

where $(\mathrm{dH} / \mathrm{dt})$ is the DSC heat flow rate. The relative crystallinity vs. crystallization time for scPLA and scPLA/ $\mathrm{GNPO}^{+}$nanocomposite have been plotted in Figure 6 .
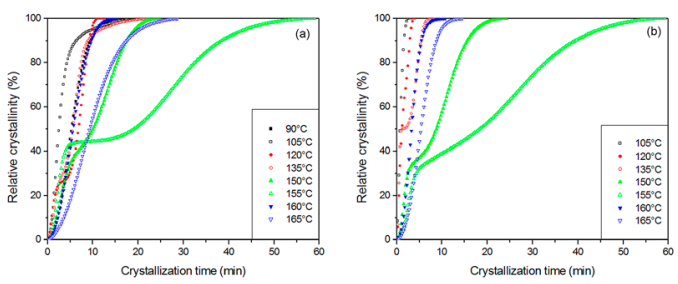

Figure 6. Relative crystallinity vs. time at various crystallization temperatures for (a) scPLA and (b) scPLA/GNPO+ nanocomposite.

From Figure 6, two step curves can be seen when $T_{c}$ is between 120 and $155^{\circ} \mathrm{C}$ which is related to the formation of two kinds of crystals. For both systems, the fastest crystallization rate occurs at $105^{\circ} \mathrm{C}$, when both kinds of crystals are formed almost simultaneously.

The crystallization kinetics of these scPLA materials under isothermal crystallization were analyzed by the Avrami equation $^{28-30}$ :

$$
\propto=1-\exp \left(-k t^{n}\right)
$$

where $\mathrm{k}$ is the crystallization rate constant and $\mathrm{n}$ is the Avrami exponent. The double logarithm of the above equation was taken to obtain the Avrami exponent $\mathrm{n}$ and crystallization rate $\mathrm{k}$ from the slope and linear coefficient of the $\ln [-\ln (1-\alpha)]$ vs. $\ln t$ plots at different $T_{c}$. Figures $7 \mathrm{a}$ and $7 \mathrm{~b}$ show these plots for scPLA and scPLA/GNPO nanocomposite, respectively.

At $T_{c}$ of 90 and $105^{\circ} \mathrm{C}$, it was not possible to perform the Avrami study since both kinds of crystals were formed at the same time. The data obtained from the plots and Avrami equation are resumed in Table 2. In general, the value of the Avrami exponent $n$ is dependent on the nucleation mechanism, as well as on the geometry of crystal growth. The analysis of the curves was done in such way that the calculation of $n$ was carried out separately for the two crystallization events. Avrami exponents obtained for the sc-crystals were around 2, suggesting a disc-like growth. For the homocrystals, $n$ varied from 2 to 4 as the $T_{c}$ decreased, which implies a change of crystal growth from a disc-like to spherulitic growth under these experimental conditions.

The time at which the extent of crystallization reaches $50 \%$, i.e., the half-time of crystallization $\left(t_{1 / 2}\right)$ is also a very important crystallization kinetics parameter. Usually, it is 

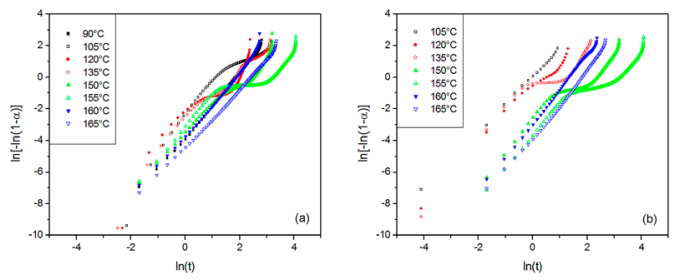

Figure 7. Avrami analysis for (a) scPLA and (b) scPLA/GNPO+ nanocomposite isothermally crystallized at various crystallization temperatures. employed to characterize the crystallization rate directly, once the reciprocal half-time of crystallization $\left(1 / t_{1 / 2}\right)$ is approximately proportional to the crystal growth rate $(G)^{31}$. Longer is the half-time of crystallization, slower is the crystallization rate. Furthermore, from $n$ and $k, t_{1 / 2}$ can be obtained from:

$$
t_{1 / 2}=\left(\frac{\ln 2}{k}\right)^{1 / n}
$$

Table 2 shows also the half-time of crystallization calculated by the mentioned equation. It was not possible

Table 2. Avrami kinetic parameters for the crystallization of scPLA and scPLA/GNPO+ nanocomposite.

\begin{tabular}{|c|c|c|c|c|c|c|c|c|c|c|c|c|c|}
\hline \multirow[b]{2}{*}{ Material } & \multirow[b]{2}{*}{$\begin{array}{l}T_{c} \\
\left({ }^{\circ} \mathbf{C}\right)\end{array}$} & \multicolumn{6}{|c|}{ Sc-crystal } & \multicolumn{6}{|c|}{ Homocrystal } \\
\hline & & $\mathbf{n}$ & $\ln (k)$ & $\mathbf{k}\left(\mathrm{s}^{-\mathrm{n}}\right)$ & $\begin{array}{c}\text { calculated } \\
\mathbf{t}_{1 / 2}(\mathrm{~min})\end{array}$ & $\underset{(\min )}{\mathbf{t}_{\max }}$ & $\begin{array}{c}\text { calculated } \\
t_{\max }(\min )\end{array}$ & $\mathbf{n}$ & $\ln (k)$ & $\mathbf{k}\left(\mathbf{s}^{-\mathrm{n}}\right)$ & $\begin{array}{c}\text { calculated } \\
\mathbf{t}_{1 / 2}(\mathrm{~min})\end{array}$ & $\begin{array}{c}\mathbf{t}_{\max } \\
(\min )\end{array}$ & $\begin{array}{c}\text { calculated } \\
\mathbf{t}_{\max } \text { (min) }\end{array}$ \\
\hline \multirow{6}{*}{ scPLA } & 120 & 2.01 & -1.95 & $1.42 \mathrm{E}-01$ & 2.2 & 1.0 & 1.9 & 4.03 & -8.21 & $2.72 \mathrm{E}-04$ & 7.0 & 7.9 & 7.2 \\
\hline & 135 & 2.05 & -2.53 & 7.97E-02 & 2.9 & 1.5 & 2.5 & 3.00 & -5.72 & $3.28 \mathrm{E}-03$ & 6.0 & 6.2 & 5.9 \\
\hline & 150 & 2.00 & -3.10 & $4.50 \mathrm{E}-02$ & 3.9 & 3.0 & 3.3 & 2.70 & -6.88 & $1.03 \mathrm{E}-03$ & 11.2 & 12.4 & 10.8 \\
\hline & 155 & 2.02 & -3.33 & $3.58 \mathrm{E}-02$ & 4.3 & 3.7 & 3.7 & 2.11 & -6.91 & $9.98 \mathrm{E}-04$ & 22.2 & 21.9 & 19.5 \\
\hline & 160 & 1.98 & -3.98 & $1.87 \mathrm{E}-02$ & 6.2 & 5.2 & 5.2 & - & - & - & - & - & - \\
\hline & 165 & 1.97 & -4.53 & $1.08 \mathrm{E}-02$ & 8.3 & 7.2 & 7.0 & - & - & - & - & - & - \\
\hline \multirow{6}{*}{$\begin{array}{l}\text { scPLA/ } \\
\mathrm{GNPO}^{+}\end{array}$} & 120 & 2.12 & 0.18 & 1.20 & 0.8 & 0.6 & 0.7 & 3.44 & -2.89 & $5.56 \mathrm{E}-02$ & 2.1 & 2.3 & 2.1 \\
\hline & 135 & 2.28 & 0.52 & 1.68 & 0.7 & 0.6 & 0.6 & 3.01 & -4.56 & $1.05 \mathrm{E}-02$ & 4.0 & 4.4 & 4.0 \\
\hline & 150 & 2.25 & -1.19 & $3.04 \mathrm{E}-01$ & 1.4 & 1.3 & 1.3 & 2.30 & -5.72 & $3.28 \mathrm{E}-03$ & 10.3 & 10.9 & 9.4 \\
\hline & 155 & 2.12 & -2.33 & $9.73 \mathrm{E}-02$ & 2.5 & 2.3 & 2.2 & 2.04 & -6.90 & $1.01 \mathrm{E}-03$ & 24.6 & 23.6 & 21.2 \\
\hline & 160 & 2.09 & -2.97 & $5.13 \mathrm{E}-02$ & 3.5 & 3.1 & 3.0 & - & - & - & - & - & - \\
\hline & 165 & 1.90 & -3.62 & $2.68 \mathrm{E}-02$ & 5.5 & 4.8 & 4.5 & - & - & - & - & - & - \\
\hline
\end{tabular}

Table 3. Transition temperatures, enthalpies and degree of crystallization of scPLA and scPLA/GNPO+ nanocomposite.

\begin{tabular}{|c|c|c|c|c|c|c|c|c|c|c|c|c|}
\hline \multirow[b]{2}{*}{ Material } & \multirow[b]{2}{*}{$\mathrm{T}_{\mathrm{c}}\left({ }^{\circ} \mathrm{C}\right)$} & \multicolumn{5}{|c|}{ Stereocrystal } & \multicolumn{6}{|c|}{ Homocrystal } \\
\hline & & $\begin{array}{l}\mathbf{T}_{\mathrm{m1}} \\
\left({ }^{\circ} \mathbf{C}\right)\end{array}$ & $\mathrm{T}_{\mathrm{m} 2}\left({ }^{\circ} \mathrm{C}\right)$ & $\Delta \mathbf{H}_{\mathrm{m}}(\mathrm{J} / \mathrm{g})$ & $\begin{array}{c}\Delta \mathbf{H}_{\mathrm{c}} \\
(\mathrm{J} / \mathrm{g})\end{array}$ & $X_{\mathrm{c}}(\%)$ & $\begin{array}{c}T_{\text {ch }} \\
\left({ }^{\circ} \mathrm{C}\right)\end{array}$ & $\begin{array}{l}\Delta \mathbf{H}_{\mathrm{ch}} \\
(\mathbf{J} / \mathbf{g})\end{array}$ & $\mathrm{T}_{\mathrm{m}}\left({ }^{\circ} \mathrm{C}\right)$ & $\Delta \mathbf{H}_{\mathrm{m}}(\mathrm{J} / \mathrm{g})$ & $\Delta \mathbf{H}_{\mathrm{c}}(\mathrm{J} / \mathrm{g})$ & $X_{\mathrm{c}}(\%)$ \\
\hline \multirow{8}{*}{ scPLA } & 90 & - & 213.7 & 25.4 & 41.2 & 16.4 & - & - & 168.4 & 30.8 & - & 29.0 \\
\hline & 105 & - & 214.2 & 15.0 & 27.4 & 9.7 & - & - & 171.0 & 21.9 & - & 20.7 \\
\hline & 120 & - & 212.5 & 26.0 & 11.9 & 16.8 & - & - & 167.7 & 37.6 & 29.7 & 35.4 \\
\hline & 135 & - & 213.2 & 20.8 & 11.9 & 13.4 & - & - & 170.9 & 36.5 & 28.5 & 34.4 \\
\hline & 150 & - & 213.5 & 19.5 & 23.4 & 12.6 & - & - & 174.4 & 35.4 & 36.4 & 33.4 \\
\hline & 155 & 198.9 & 214.4 & 21.1 & 24.7 & 13.6 & - & - & 176.2 & 36.3 & 34.0 & 34.3 \\
\hline & 160 & 201.0 & 215.2 & 21.0 & 20.4 & 13.6 & 92.4 & 13.3 & 169.4 & 25.5 & - & 11.5 \\
\hline & 165 & 204.4 & 215.7 & 24.4 & 24.6 & 15.7 & 91.9 & 12.8 & 168.9 & 25.7 & - & 12.1 \\
\hline \multirow{7}{*}{$\begin{array}{l}\text { scPLA/ } \\
\mathrm{GNPO}^{+}\end{array}$} & 105 & - & 216.0 & 18.7 & 13.0 & 12.1 & - & - & 169.5 & 29.0 & 25.8 & 27.3 \\
\hline & 120 & - & 214.7 & 24.8 & 13.5 & 16.0 & - & - & 165.9 & 37.8 & 31.9 & 35.7 \\
\hline & 135 & - & 213.7 & 22.6 & 16.4 & 14.6 & - & - & 169.0 & 38.8 & 32.3 & 36.6 \\
\hline & 150 & - & 215.4 & 21.6 & 21.9 & 13.9 & - & - & 173.7 & 41.0 & 38.3 & 38.7 \\
\hline & 155 & 200.2 & 216.2 & 23.0 & 25.4 & 14.8 & - & - & 174.9 & 35.2 & 30.9 & 33.2 \\
\hline & 160 & 202.5 & 216.9 & 22.9 & 34.3 & 14.7 & 91.7 & 12.9 & 167.7 & 22.4 & - & 9.0 \\
\hline & 165 & 205.2 & 217.2 & 24.9 & 35.1 & 16.1 & 91.0 & 11.5 & 167.2 & 21.9 & - & 9.8 \\
\hline
\end{tabular}

$* \Delta \mathrm{H}_{\mathrm{c}}$ was obtained from the deconvolution of the isothermal crystallization curves; $\mathrm{T}_{\mathrm{ch}}$ is the crystallization temperature on heating (cold crystallization). 
to be calculated the half-time of crystallization estimated from the relative crystallinity vs. crystallization time plots, once it should consider the crystallizations of both kinds of crystals as the $100 \%$ relative crystallinity. scPLA/GNPO+ nanocomposite had the lowest half-time of crystallization, $0.7 \mathrm{~min}$ for the sc-crystal when crystallized isothermally at $135^{\circ} \mathrm{C}$ and $2.1 \mathrm{~min}$ for the homocrystal when crystallized isothermally at $120^{\circ} \mathrm{C}$.

Another data that can be obtained from the isotherms is the time to reach the maximum rate of crystallization $\mathrm{t}_{\max }$. This value can also be used to characterize the rate of crystallization. The data of $t_{\max }$ can be readily obtained from the isotherms in Figures 4 and 5. Since $t_{\text {max }}$ corresponds to the point at which $\mathrm{dQ}(\mathrm{t}) / \mathrm{dt}=0, \mathrm{Q}(\mathrm{t})$ is the rate of heat evolution, thus:

$$
t_{\max }=\left(\frac{n-1}{n k}\right)^{1 / n}
$$

The value of $t_{\text {max }}$ can be derived from the Avrami exponent $\mathrm{n}$ and the parameter $\mathrm{k}$. Both the calculated and the extracted values of $t_{\text {max }}$ are summarized in Table 2 and are in agreement. Also in agreement with the $t_{1 / 2}$, the lowest $t_{\text {max }}$ occurs for the sc-crystal when crystallized isothermally at $135^{\circ} \mathrm{C}$ and for the homocrystal when crystallized isothermally at $120^{\circ} \mathrm{C}$.

\subsection{Thermal behavior after isothermal crystallization}

Figure 8 and 9 show DSC heating curves after the isothermal crystallization of scPLA and scPLA/GNPO+ nanocomposite, respectively. Table 3 presents the transition temperatures, enthalpies and degree of crystallinity of scPLA and scPLA/GNPO+ nanocomposite obtained from the curves. According to the curves, it can be observed the presence of endothermic peaks related to melting of both homochiral and sc-crystals regardless of the crystallization temperature. But when isothermal crystallization was performed at 160 and $165^{\circ} \mathrm{C}$, there is an exothermic peak which can be attributed to the cold crystallization of homochiral crystals that was not able to be formed during isothermal crystallization as discussed before.

The highest melting point for the homocrystal was obtained when the sample was isothermally crystallized at $155^{\circ} \mathrm{C}$, regardless of the presence of graphene. It means that this $\mathrm{T}_{\mathrm{c}}$ can induce the formation of more perfect homocrystal, independent of the presence of the nanofiller. With regard the melting of stereocrystals, it can be observed that there are double melting peaks in the DSC curves at higher crystallization temperatures, and these peaks are shifted to higher temperatures with increasing crystallization temperature. This behavior was noted for both materials, scPLA and scPLA/GNPO+ nanocomposite. The double-melting behavior of isothermally crystallized PLA homocrystals has been reported in literature ${ }^{32}$ and it is attributed to melting of crystals derived from melting and recrystallization

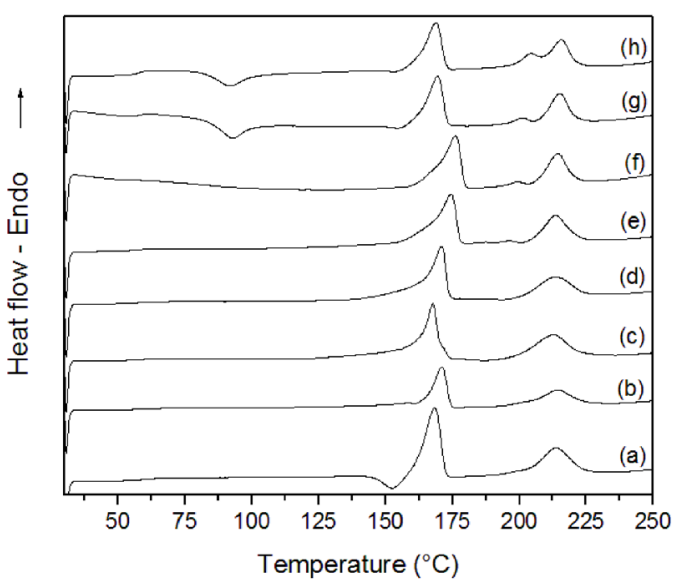

Figure 8. DSC heating curves of scPLA after isothermal crystallization at: (a) $90^{\circ} \mathrm{C}$, (b) $105^{\circ} \mathrm{C}$, (c) $120^{\circ} \mathrm{C}$, (d) $135^{\circ} \mathrm{C}$, (e) $150^{\circ} \mathrm{C}$, (f) $155^{\circ} \mathrm{C}$, (g) $160^{\circ} \mathrm{C}$ and (h) $165^{\circ} \mathrm{C}$.

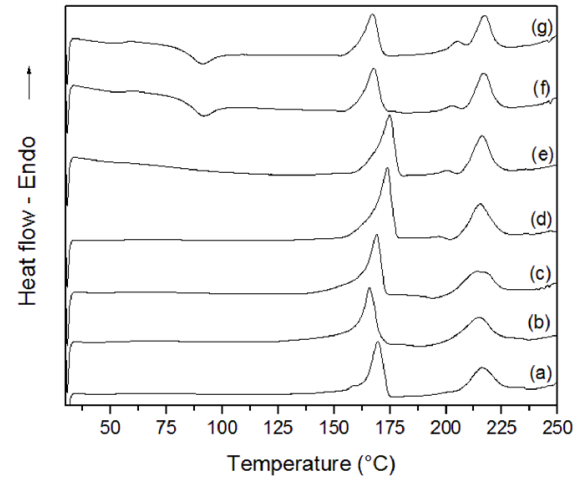

Figure 9. DSC heating curves of scPLA/GNPO+ nanocomposite after isothermal crystallization at: (a) $105^{\circ} \mathrm{C}$, (b) $120^{\circ} \mathrm{C}$, (c) $135^{\circ} \mathrm{C}$, (d) $150^{\circ} \mathrm{C}$, (e) $155^{\circ} \mathrm{C}$, (f) $160^{\circ} \mathrm{C}$ and (g) $165^{\circ} \mathrm{C}$.

processes during heating. In this work, the double melting behavior was also observed for the sc-crystals. In this case, the lower temperature peak of the double melting peaks can be attributed to melting of sc-crystals of low perfection formed at those higher crystallization temperatures and it is not clear the reasons for the crystallization temperature dependence on its formation.

\section{Conclusions}

The isothermal crystallization kinetics of stereocomplexes of symmetric PLLA/PDLA blends (scPLA) and scPLA/ $\mathrm{GNPO}+$ nanocomposite containing $0.5 \mathrm{wt} \%$ of GNPO+ was investigated by DSC. From the melt, both materials show crystallization of homo and sc-crystals of PLA which was highly influenced by the crystallization temperature. Incorporation of the graphene oxide to scPLA accelerates the crystallization process of the scPLA matrix. For instance, 
at the temperature in which scPLA has the maximum rate of crystallization $\left(120^{\circ} \mathrm{C}\right)$, its half-time of crystallization $\mathrm{t}_{1 / 2}$ was $2.2 \mathrm{~min}$, while for the same $\mathrm{T}$, scPLA/GNPO+ nanocomposite presented $\mathrm{t}_{1 / 2}=0.8 \mathrm{~min}$. In these symmetric blends, both types of crystal, homocrystals and stereocrystals can be formed during isothermal crystallization. At crystallization temperature of 160 and $165^{\circ} \mathrm{C}$, the crystallization of homocrystals is reduced and stereocomplex crystals grow predominate.

\section{Acknowledgements}

The authors are grateful to CNPq (310917/2014-0), CAPES (PNPD 2822/2011), and FAPERJ (E-26/201.304/2014) for the financial support.

\section{References}

1. Kawai T, Rahman N, Matsuba G, Nishida K, Kanaya T, Nakano $\mathrm{M}$, et al. Crystallization and Melting Behavior of poly(L-lactic Acid). Macromolecules. 2007;40(26):9463-9469.

2. Ikada Y, Jamshidi K, Tsuji H, Hyon SH. Stereocomplex formation between enantiomeric poly(lactides). Macromolecules. 1987;20(4):904-906.

3. Tsuji H, Horii F, Hyon SH, Ikada Y. Stereocomplex formation between enantiomeric poly(lactic acid)s. 2. Stereocomplex formation in concentrated solutions. Macromolecules. 1991;24(10):2719-2724.

4. Tsuji H, Hyon SH, Ikada Y. Stereocomplex formation between enantiomeric poly(1actic acid)s. 3. Calorimetric studies on blend films cast from dilute solution. Macromolecules. 1991;24(20):5651-5656.

5. Tsuji H. Poly(lactide) Stereocomplexes: Formation, Structure, Properties, Degradation, and Applications. Macromolecular Bioscience. 2005;5(7):569-597.

6. Slager J, Domb AJ. Biopolymer stereocomplexes. Advanced Drug Delivery Reviews. 2003;55(4):549-583.

7. Fan Y, Nishida H, Shirai Y, Tokiwa Y, Endo T. Thermal degradation behaviour of poly(lactic acid) stereocomplex. Polymer Degradation and Stability. 2004;86(2):197-208.

8. Silvino AC, Corrêa PS, Dias ML. Preparation of PLLA/PDLA stereocomplexes using a novel initiator based on $\mathrm{Mg}$ (II) and Ti(IV) alkoxides. Journal of Applied Polymer Science. 2014;131(18):40771-40778.

9. Łukaszczyk J, Jelonek P, Trzebicka B, Domb AJ. Stereocomplexes formation from enantiomeric star-shaped block copolymers of e-caprolactone and lactide. e-Polymers. 2010;10:798-812.

10. Michell RM, Müller AJ, Spasova M, Dubois P, Burattini S, Greenland BW, et al. Crystallization and stereocomplexation behavior of poly(D- and L-lactide)-b-poly(N,N-dimethylamino2-ethyl methacrylate) block copolymers. Journal of Polymer Science, Part B Polymer Physics. 2011;49(19):1397-1409.

11. Isono T, Kondo Y, Otsuka I, Nishiyama Y, Borsali R, Kakuchi $\mathrm{T}$, et al. Synthesis and Stereocomplex Formation of Star-Shaped Stereoblock Polylactides Consisting of Poly(L-lactide) and
Poly(D-lactide) Arms. Macromolecules. 2013;46(21):85098518.

12. Tsuji H, Takai H, Saha SK. Isothermal and non-isothermal crystallization behavior of poly(L-lactic acid): Effects of stereocomplex as nucleating agent. Polymer. 2006;47(11):38263837.

13. Wei XF, Bao RY, Cao ZQ, Yang W, Xie BH, Yang MB Stereocomplex Crystallite Network in Asymmetric PLLA/ PDLA Blends: Formation, Structure, and Confining Effect on the Crystallization Rate of Homocrystallites. Macromolecules. 2014;47(4):1439-1448.

14. Wei XF, Bao RY, Cao ZQ, Zhang LQ, Liu ZY, Yang W, et al. Greatly accelerated crystallization of poly(lactic acid): cooperative effect of stereocomplex crystallites and polyethylene glycol. Colloid and Polymer Science. 2014;292(1):163-172.

15. Bouapao L, Tsuji H. Stereocomplex Crystallization and Spherulite Growth of low Molecular Weight Poly(L-lactide) and Poly(D-lactide) from the Melt. Macromolecular Chemistry and Physics. 2009;210(12):993-1002.

16. Na B, Zhu J, Lv R, Ju Y, Tian R, Chen B. Stereocomplex Formation in Enantiomeric Polylactides by Melting Recrystallization of Homocrystals: Crystallization Kinetics and Crystal Morphology. Macromolecules. 2014;47(1):347-352.

17. Nam JY, Okamoto M, Okamoto H, Nakano M, Usuki A, Matsuda M. Morphology and crystallization kinetics in a mixture of low-molecular weight aliphatic amide and polylactide. Polymer. 2006;47(4):1340-1347.

18. Martínez de Arenaza I, Sarasua JR, Amestoy H, Lopez-Rodriguez N, Zuza E, Meaurio E, et al. Polylactide stereocomplex crystallization prompted by multiwall carbon nanotubes. Journal of Applied Polymer Science. 2013;130(6):4327-4337.

19. Sun Y, He C. Synthesis, stereocomplex crystallization, morphology and mechanical property of poly(lactide)-carbon nanotube nanocomposites. RSC Advances. 2013;3(7):2219-2226.

20. Sun Y, He C. Synthesis and Stereocomplex Crystallization of Poly (Lactide)/Graphene Oxide Nanocomposites. ACS Macro Letters. 2012;1(6):709-713.

21. Sawai D, Tsugane V, Tamada M, Kanamoto T, Sungil M, Hyon SH. Crystal density and heat of fusion for a stereo-complex of poly(L-lactic acid) and poly(D-lactic acid). Journal of Polymer Science, Part B Polymer Physics. 2007;45(18):2632-2639.

22. Sarasua JR, Rodríguez NL, Arraiza AL, Meaurio E. Stereoselective Crystallization and Specific Interactions in Polylactides. Macromolecules. 2005;38(20):8362-8371.

23. Brizzolara D, Cantow HJ, Diederichs K, Keller E, Domb AJ. Mechanism of the Stereocomplex Formation between Enantiomeric Poly(lactide)s. Macromolecules. 1996;29(1):191-197.

24. Zhang J, Tashiro K, Tsuji H, Domb AJ. Disorder-to-Order Phase Transition and Multiple Melting Behavior of poly(L-lactide) Investigated by Simultaneous Measurements of WAXD and DSC. Macromolecules. 2008;41(4):1352-1359.

25. Woo EM, Chang L. Crystallization and morphology of stereocomplexes in nonequimolar mixtures of poly(L-lactic acid) with excess poly(D-lactic acid). Polymer. 2011;52(26):60806089 . 
26. Androsch R, Schick C, Di Lorenzo ML. Melting of conformationally Disordered Crystals ( $\alpha^{\prime}$-phase) of Poly(L-lactic acid). Macromolecular Chemistry and Physics. 2014;215(11):11341139.

27. Righetti MC, Gazzano M, Di Lorenzo ML, Androsch R. Enthalpy of melting of a\&apos;- and a-crystals of poly(L-lactic acid). European Polymer Journal. 2015;70:215-220.

28. Avrami M. Kinetics of Phase Change. I General Theory. Journal of Chemical Physics. 1939;7(12):1103-1112.

29. Avrami M. Kinetics of Phase Change. II Transformation Time Relations for Random Distribution of Nuclei. Journal of Chemical Physics. 1940;8(2):212-224.
30. Avrami M. Granulation, Phase Change, and Microstructure Kinetics of Phase Change. III. Journal of Chemical Physics. 1941;9(2):177-183.

31. Iannace S, Nicolais L. Isothermal crystallization and chain mobility of poly(L-lactide). Journal of Applied Polymer Science. 1997;64(5):911-919.

32. Souza DHS, Andrade CT, Dias ML. Isothermal crystallization kinetics of poly(lacticacid)/synthetic mica nanocomposites. Journal of Applied Polymer Science. 2014;131(11):4032240330 . 